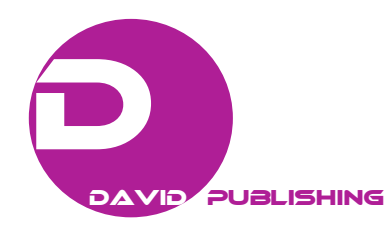

\title{
Rehabilitation of Abandoned Monumental Hospitals: Tools for Urban Liveability
}

\author{
Pier Francesco Cherchi \\ Dipartimento di Ingegneria Civile, Ambientale e Architettura, Università degli Studi di Cagliari, Cagliari 09123, Italy
}

\begin{abstract}
This proposal is intended to be a contribution toward achieving more liveable cities through the revitalization of inner areas based on the restoration and rehabilitation of historic facilities in order to meet current needs. The research starts by posing the following questions. Can we claim, in a general perspective of improvement of the quality of life in towns and cities, that the recovery of abandoned historic buildings could be a key-factor in conservation and innovation policies of the historical heart of towns? What relationship, if any, is there between the adaptive-reuse design of ancient hospitals and the effects of such action, not only in terms of heritage conservation but also in terms of economic and social regeneration of the surrounding context? The complexity of this issue is addressed by analyzing related cases, relevant for their design solutions and effects, and proposes answers to the opening questions by correlating the main characters of relevant case studies in Europe.
\end{abstract}

Key words: Adaptive reuse, sustainable preservation, sustainable preservation, historic hospitals, recycling.

\section{Introduction}

"Memory enables us to revisit our experience, to learn from the past, and even to plan what to do in the future. Memory does more than just help us survive, it influences our quality of life and helps us shape our identity" [1].

This impressive statement by Suzanne Corkin, the scientist who studied the case of Henry Molaison, who underwent experimental surgery in the fifties, during which his long-term memory centres were resected, reinforces our conviction that "monuments", especially collective one, such as traditional hospitals, are not only metaphorically, the inescapable assumption of future project: “... our identity is composed of narratives we construct based on our personal history" [1].

Nowadays, an increasing number of European cities are experimenting with interdisciplinary and collective strategies for rehabilitating their unused built memories, layers of community's history:

Corresponding author: Pier Francesco Cherchi, Ph.D. architect, assistant professor, research fields: architecture design and heritage design.
- industrial and residential buildings that have become empty or underutilized,

- open spaces that have been abandoned and forgotten.

In investigating the theme of adaptive reuse of a city's unused places, it is important to note certain differences between European and North American cities. In the United States, after World War II, the rise of the middle class brought about the gradual abandonment of blighted areas in the vicinity of large factories, the birth and explosive expansion of the suburbs, and the abandonment of the inner cities. Since then the gradual dismantling of the manufacturing industries and the conversion of the economy to service, research and technological innovation sectors have triggered massive processes of depopulation and abandonment of entire cities, which have often, especially in the so-called "rust belt" cities, taken on an apocalyptic character and imposing size [2]. In Europe, on the other hand, the origins and implications of this phenomenon have been profoundly different. In most medium and small-sized cities, the processes of abandonment of buildings and terrain have been slow and silent and have mainly affected the interstices of 
the city and ancient and modern relics. After the demolition of the medieval defensive walls, which occurred mainly in the 19th century, European cities have superseded their historical limits and initiated a process of occupation of their outlying territories, triggering a rapidly expansive, centrifugal movement which has generated extensive urban sprawl, characterized by high-rise buildings interspersed with empty extensions often devoid of identity. The relationship between the center and the outskirts, between the historic city and the new modern districts, has often been contentious and has rarely been carried out without negative side effects: the forceful urban thrust toward the periphery has left behind it a hidden geography of buildings and spaces that are abandoned or underused. While urban planners, architects and administrators have focused their attentions on a polycentric model, the urban areas of the 19th and the first half of the 20th century have been left behind: small and large public buildings have been deprived of their original functions, which have been decentralized in the new big containers of the expanded city, while large and small inner city spaces have remained hidden behind their tall city walls, inaccessible and unexplorable. All European cities are full of these places. Conflicts between public and private interests and the lack of adequate sensitivity have prevented them from being appraised as precious urban artifacts. Nowadays, when the pressure on infrastructures is evident and resources are decreasing, European cities, hit by the economic crisis, have ceased their outward expansion and turned back toward their forgotten centers. Thus, administrators, architects, planners, contractors and citizens have initiated a process of reassessing what exists, whose aim is to rethink the city in terms of liveability, sustainability and health.

Cities enacting policies aimed at creating a more liveable and healthier ambience are regarding their existing resources with great attention and interest. Reusing spaces and buildings that have become obsolete is an important strategy for sustainable development and a relevant answer to the excessive use of resources resulting from the destruction and redevelopment of the existing stock.

After having explored the literature and the state of scientific research into the reasons of those who argue that reuse will help build a more sustainable and liveable city, this research tries to make a contribution to the debate and new instruments for evaluating actions to undertake in order to make cities healthier place in which to live.

\section{Ideas and Discussion: Tools and Parameters for Achieving Healthier and More Liveable Cities through Regeneration of Abandoned Historic Buildings and Related Places with Cultural Values}

Currently, cities are discovering a hidden, unexpected treasure: unused places and buildings, disused urban factories, abandoned interstitial spaces, large civic buildings no longer suitable for hosting the functions for which they were designed. It is in this phase that the need for change presents itself: demolition to make way for a new construction or some form of reconstruction or reutilization.

Especially in Europe, this heritage is a great potential to refer to in order to improve already activated policies for making cities more hospitable and liveable. The reasons are complex and detailed, and this document does not seek to demonstrate effectiveness and benefits, but, starting with an analysis of the scientific literature on this subject, the paper will outline the main relationships between the healthy city project and existing practices of reutilization. Subsequently, these relationships will be explored by analyzing sixteen case studies, and the potential of adaptive reuse for achieving healthier cities will be tested by comparing solutions and effects of architectural design.

The ongoing debates on urban sustainability tend to focus on technical issues, such as the reduction of heat dispersion in buildings, waste management, harmful 
emissions into the atmosphere, or on the economic aspects of urban planning, or technical aspects of the restoration, such as the ways and means for conserving historical relics. Increasingly, however, governments recognize the role that the existing city, and particularly its cultural heritage, plays for the social welfare of different groups living within increasingly cosmopolitan cities [3]. So, in the specific case of the historic buildings that, while having been abandoned, they are also part of a cultural heritage [4]. If certainly the idea of demolishing them cannot be practiced on account of the legislative protection meant to protect them from reckless actions, certainly no one could even imagine a fate other than restoration and reutilization of buildings that contribute to the cultural identity and sense of belonging to a place of a whole community [5]. The shared assumption underlying these statements is that the buildings are carriers of meanings and values. Tweed and Sutherland [3] point out how the research undertaken in the sixties by Kevin Lynch, and subsequently developed by scholars of environmental psychology, it was based on the assumption that buildings are carriers of meanings and that citizens perceive them in relation to the meanings they are able to recognize and associate to them [6]. In particular, Tweed and Sutherland [3] underline how Amos Rapoport, in distinguishing the meanings in three different levels, locates in the upper one fundamental values related to the cultural patterns, philosophical systems and religious identity of a community [7]. These symbolic meanings are completely absent in the contemporary environment and are a unique intangible value in a historical heritage. Citizens associate historic buildings with meanings that are the basis of the sense of belonging to a community and of local identity, and, therefore, safeguarding buildings have positive impacts and promote the conditions that make cities safer and more liveable places.

Walkability and bikeability are two factors that contribute to strengthening the relationship between the health improvement of a city and the reutilization of its abandoned centrality. Clearly, the reutilization of buildings and unused structures helps to multiply a city's functions and opportunities accessible from several points through public transport, bikes or walking. Walkability and bikeability are important components in policies aimed at promoting liveability and creating healthy living environments. In terms of urban sustainability, compactness and density are recognized qualities which play an important role because they contribute to shortening distances and encouraging sustainable mobility [8].

In this regard, Stephen Marshall says that a city should therefore promote and encourage pedestrian-friendly street design as an opportunity for reducing air pollution, the social costs of individual transportation and automobile dependency. Moreover, all this helps to increase the sense of belonging to a place and a sense of community [9]. Moreover, it helps to emphasize the fact that the walkability of an urban center is not simply determined by proximity, but that other factors such as the design of the routes and public spaces, contribute heavily. However, one of the conditions that motivate citizens to give up private cars and travel by bicycle or on foot is that attractive places and collective services are easily accessible. For these reasons, the design of the adaptive reutilization of buildings contributes to the project of a more liveable and healthier city.

In reflecting on the links between the liveability and economy of a city, Moretti [10] argues that many cases cities gain in appeal because they succeed in building a solid economic base, and not vice versa. Citing the case of Seattle, as an example of a city that over the years has undergone decay and abandonment, he states that the processes of economic revival are not directly triggered by the attractiveness and liveability of the urban environment. However, Moretti does not exclude that the attractiveness that a city is able to exert on business and investments can be encouraged by the policies of urban regeneration that, as in the case of Seattle, are focused on the recovery and reutilization of 
buildings and the abandoned spaces of the 20th century city: crumbling warehouses were recovered to make room for dozens of small startups and the economic revitalization of a city is accompanied by projects for restoring pieces of abandoned cities [10].

The perception that losing a piece of heritage is a memory, shared values and identity leak, is to a large extent, especially in Europe, shared and recognized. However, in addition to this, economic implications are decisive in the reactivation and revitalization of derelict buildings: this is because the asset evaluations are mainly carried out with the sole purpose of investment recapitalization. In several examined cases, this aspect significantly determines the new function and the fate of the factory. From its own side of the great architectural and typological quality, size and the rational layout of the rooms, it is such as to constitute a "critical mass" sufficient to trigger the rehabilitation process. From another side, the large size and the functional stiffness makes difficult, at least on the economic level, the conservation and the maintenance of a public function. Indeed, if we consider that in Europe the majority of historian hospitals were public facilities, frequently the challenge of recovery, the conversion to new uses and the management of "large urban containers", has determined the slow abandonment and the consequent lack of interest. The building monument deprived of original function, is progressively perceived a "problem" rather than for the community. From this point of view, it seems emblematic the destinies of two 19th-century hospitals in Berlin: the Bethanien in Mariannenplatz and the Am Urban in Berlin. The first one was a public building and today is a Künstlerhaus, a home for artists. Under the control of the city council, it is one of the hearts of the Berlin culture buttons of the third millennium. The second, is a 19th century complex formed by 19 schinkelian pavilions, in the Kreuzberg District. These experiences, in many ways, are particularly interesting as case studies of the scenarios assessed in a capital and divergent managerial cases, the first public, the second private; But also for the collective role that in both cases, although with different meanings and implications, it was maintained not to distort and not erase the collective memory of the original function. Particularly, this paper wishes to emphasize as well the residential conversion has not prevented the central park - the former garden that once ensured the circulation of air between the pavilions of infirmaries according to those that were hygiene standards defined by knowledge prophylaxis and hygiene, has now maintained a social role as an open public garden, permeable to the city and neighbourhood.

The practices of reutilization are central for reinserting in the network of a city's active places and spaces derelict yards and forgotten open spaces. These are often impeded spaces, or courtyards attached to industrial or residential buildings that originally had a direct relation to the buildings, authentic outdoor extensions of the activities that took place there. Usually these places are inaccessible, separated from the city by high walls and insurmountable barriers. Rethinking abandoned buildings and adaptive reutilization makes it possible to rethink ties and connections between open spaces and buildings [11], start up new relationships with the city by breaking down perimeters of separation and open up new connections. In this way, the potentialities of the reutilization of forgotten urban spaces are remarkable: covered spaces offer new opportunities for regenerating a city, engaging in new relationships, building new squares, and activating new unexpected connections between the different parts of a city.

\section{Exploring Findings and Implications: Main Relationships between the Healthy City Project and Existing Practices of Reutilization}

In the initial phase of investigation, the author posed certain preliminary questions in order to mark off our topic and the range of our research.

What is the potential of abandoned monumental 
buildings for renewing and regenerating inner-city areas? What future do we imagine for those old buildings that historically have played a significant role in the civic consciousness of a community and that still contribute to forming the memory and cultural identity of a society? Can we suppose that the recovery of abandoned buildings could be a virtuous practice, not only in terms of sustainability for their enormous potential, but also for the role that public landmark centrality can play in social revitalization and urban regeneration?

The complexity of this issue is addressed by analyzing related cases, relevant for their design solutions and effects. During the last 15 years, the adaptive-reuse of abandoned civic facilities, especially hospitals, has been a core issue in the debate on the future of cities [12]. Through an analysis of case studies, several examples emerge which a great deal about practicable solutions can be told.

It should be considered that, in most cases, 18th- and 19th-century hospitals are very remarkable works of architecture. Furthermore, these buildings, because of the relevant role they played in the past, make a powerful contribution to forming the cultural identity of a community. There is a general popular sentiment against abandoning or even demolishing them. In most cases, these buildings are located in inner city areas, which makes them easily accessible and constitutes a great opportunity for renovating the surrounding spaces and facilities.

Several recent European experiences encourage the

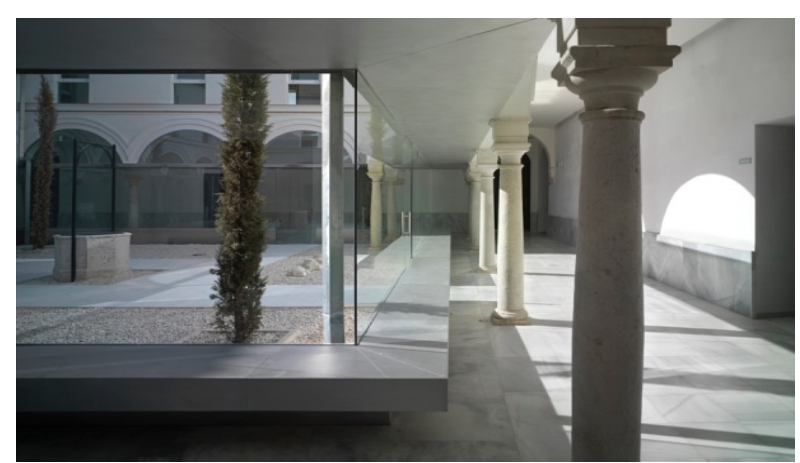

Fig. 1 Former San Jeronimo Hospital, in Marchena (Spain): it has been converted to community offices and spaces for social activities. choice of adaptive reuse, a term that refers to the revitalization of abandoned urban areas or abandoned buildings. Adaptive reuse signifies converting old buildings to new uses that are compatible with existing needs and realities. Adaptive reuse helps to preserve the history and identity of a community, as well as to stimulate private investments for the introduction of innovative functions capable to attract private funds [13].

In several cases, the new function is a hotel: the Vighi Hospital in the Italian City of Parma, an 19th-century building, was recently converted into a five-star hotel, an enterprise financed with private funds. The Bethanien Hospital in Berlin is a 19th-century building which, with the use of public funds, was converted into the Kunstlerhaus, a broad complex dedicated to art, culture and education. The Am Urban Krankenhause in Berlin was recently converted, with the use of private funds, into private offices and homes. Fig. 1 shows the former San Jeronimo Hospital which was converted to an administration center, with offices and spaces for social activities. There are many other relevant cases examined, which for brevity they are not named. The odd part of this story is that in most experiences these buildings have been converted to a new, completely different function, whose positive aspect is the new life to which they have given rise. Sometimes the only sign of their glorious past is, as in the Bethanien Hospital, the old pharmacy room with its original furniture.

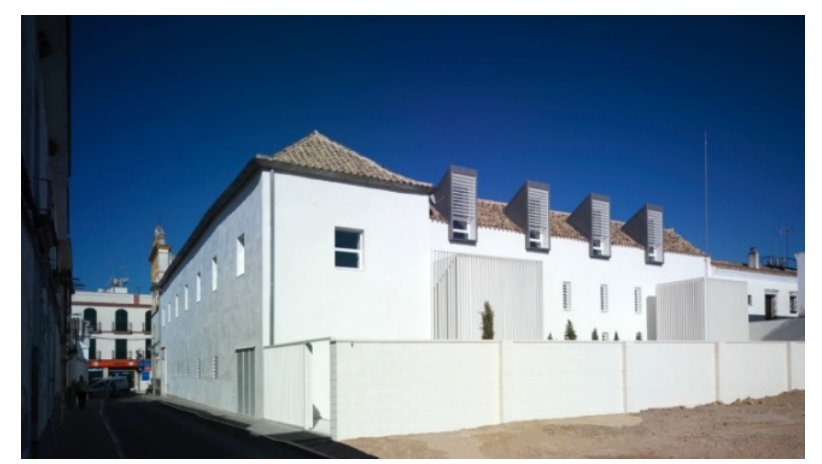

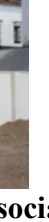


The paper aims to investigate the opportunity of revitalizing derelict urban spaces based on the restoration and rehabilitation of historic hospitals. Answers to the opening questions are suggested by investigating the following case studies that have been studied one by one and in mutual relationships:

- former Vighi Hospital, Parma, Italy;

- former Bethanien Hospital, Berlin, Germany;

- former Am Urban Kreuzberg Hospital, Berlin, Germany;

- Otto Wagner Hospital, Wien, Austria;

- former Meindlhaus Hospital, Sarleinsbach, Austria;

- former St Jeronimo Hospital, Sevilla, Spain;

- former Radcliffe Infirmary Hospital, Oxford, Great Britain;

- Military Hospital, Antwerp, Belgium;

- former Richaud Hospital, Versailles, France;

- former Ex Royal Fredriks Hospital, Copenhagen, Denmark;

- former Hospital de la Misericordia Hospital, Elvas, Portugal;

- former S. Teotonio de Santa Casa Misericordi Hospital, Viseu, Portugal;

- former Caroline Hospital, Marsiglia, France;

- former Capilla Hospital, Sant Sadurnì d'Anoia, Spain;

- former Isola di Sacca Sessola Hospital, Venezia, Italy;

- former Santa Maria Hospital, Siena, Italy.

Abandoned hospitals need to be analyzed and evaluated in a specific way. Often, they have an exceptional significance on account of the notable infrastructures, which distinguish them from other types of buildings in disuse. Historic hospitals in Europe and the rest of the world share a common destiny: fitted out in the past with innovative typological and morphological features, they have become obsolete: made in the past with innovative type, morphological characteristics, outdated today. The complexity of this theme can be addressed beginning with the following questions: what can be done with historic monumental hospitals? How should we deal buildings initially conceived to be as places of care and treatment that are no longer capable of serving as a modern facility? What future can we conceive for historic hospitals, and for all other civic facilities, in order to achieve a healthier city?

The case study described in the following pages is a research project divided into several phases starting from an analysis of historical documents, and an in-depth knowledge of the current situation, in order to determine potential and compatible features [14]. The case study is chosen as a prime example for investigating how the renewal of a structure that is underutilized and destined for abandonment may trigger virtuous processes in order that can achieve the objectives of health and liveability of an urban environment.

An important aspect is accessibility, but more than that, in most cases, like in the ancient hospital of Olot, in Spain, the ground floor program is strategic for creating a link to the community (Fig. 2). An indeterminate space, directly connected to the street, was converted to the new tourist office. Here, architects developed a strategy based on the city and its surroundings values-landscape, history, culture and identity, but also oriented to enhance the involvement in the urban plot in order to make it recognizable as an open public building and as a part of public space. The connection with the city and the activation of new relationships is one of the key peculiarities of the project. In this case, like in most selected, design is oriented to maintain the historic character while also create a new image, different from a traditional hospital, so that users will be encouraged to enter and feel like at home in a relaxed, hospitable environment.

Considering the findings of the literature review and the analysis of the selected case studies, it shows up a plausible correlation between actions of adaptive reuse and the desired objectives of health and liveability of the city. 

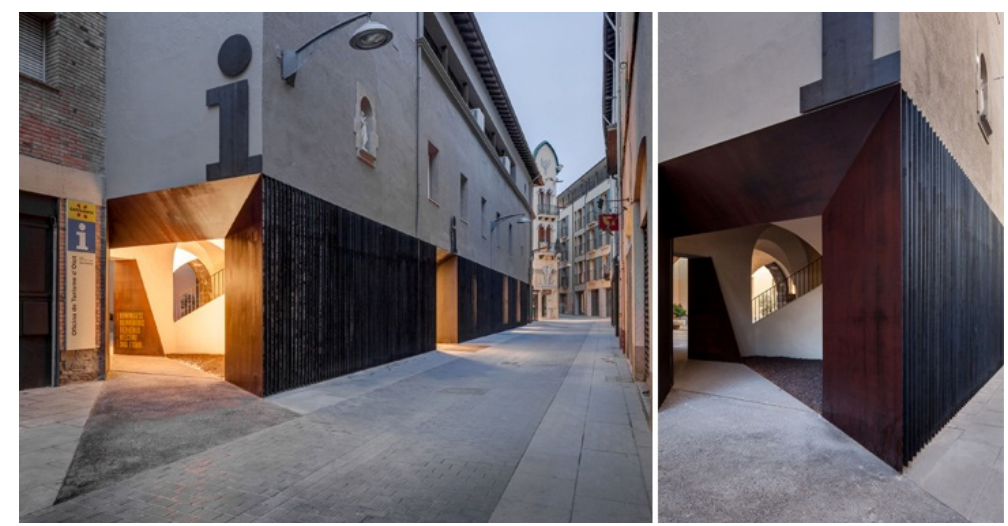

Fig. 2 Former Olot Hospital (Spain): ground floor accessibility.

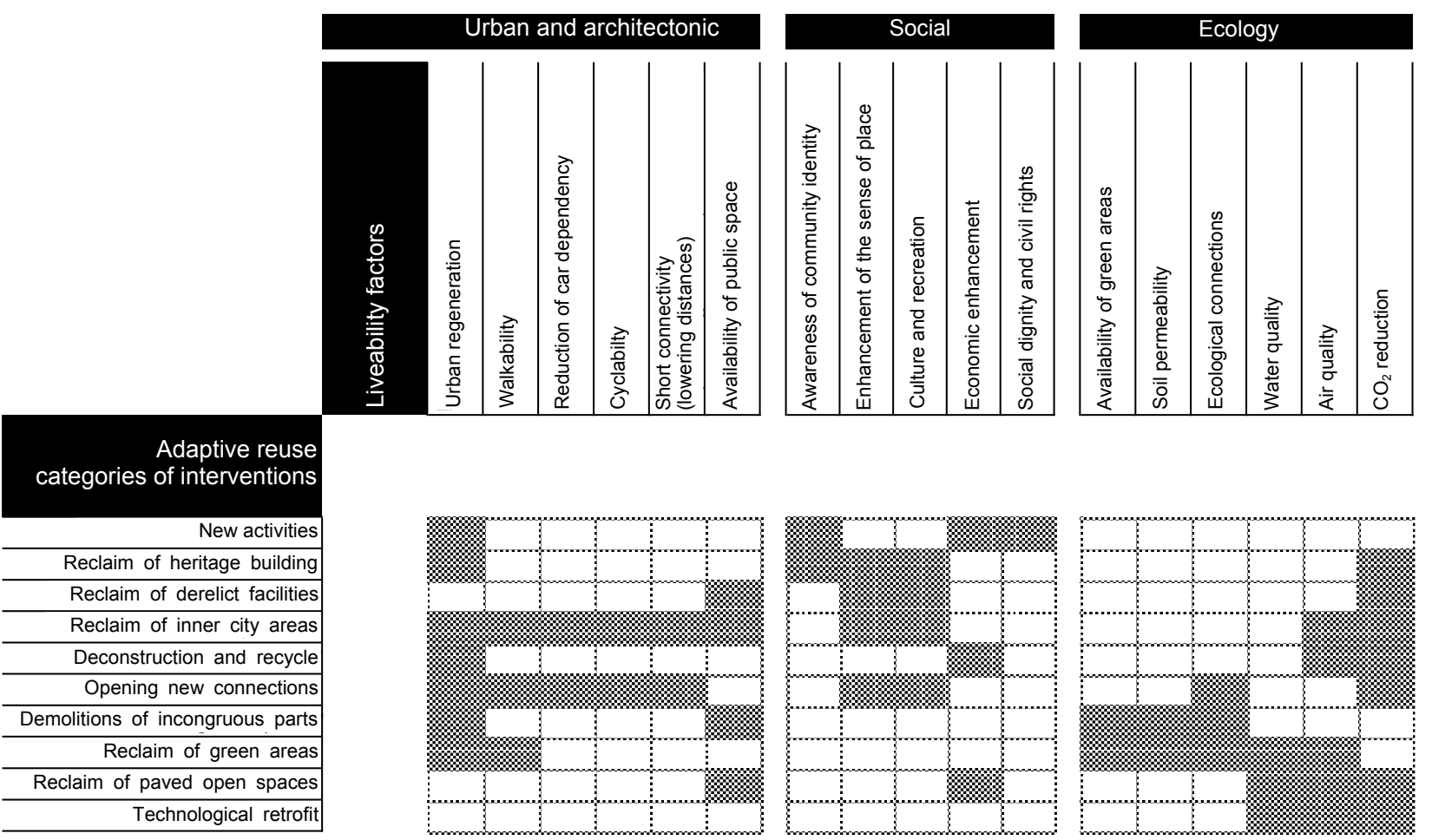

Fig. 3 Correlation between actions of adaptive reuse and the desired objectives of health and liveability of the city.

With this perspective, a set of specific categories of intervention has been recognized: new activities, reclaim of heritage building, reclaim of derelict facilities, reclaim of inner areas, deconstruction and recycle, opening of new connections, demolitions of incongruous parts, reclaim of green areas, reclaim of paved open spaces and technological retrofit. Beside interventions, the analysis focused on "livability factors" reached through design solutions and strategies of interventions. These quality values were divided into three categories:
- urban and architectonic;

- social;

- ecology.

The first one is mainly related to an aspect of the urban regeneration, connectivity and consistency of public space that interventions made available. Another crucial factor of attention is determined by social factors which emerged as positive effects of interventions. Among them, there are "awareness of community identity", "enhancement of the sense of place", "economic enhancement" and "social dignity 
and civil rights". Ecology is the third category of attention, mainly related to the quality of air, water, soil and the availability of green areas as a result of design actions.

Once defined the framework of parameters, the research was developed through critical analysis of projects, conducted by identifying the specific categories of interventions and associating them to the livability factors activated through design. Fig. 3 summarizes the correlations between livability aspects and categories of adaptive reuse interventions: It highlights how some actions partially act on certain parameters of urban living, and others specifically activate others. Consequently, the project, in each case, should identify actions and guide choices in order to enable the spectrum of virtuous scenarios which influence the quality of an urban settlement.

This chart should not be considered exhaustive of all factors that can determine choices of the various actors: administrators, architects, town planners, citizens' associations and stakeholders who are called to define future scenarios. However, a simplification and a reduction is necessary in order to enable a lucid decision making driven by clear categories and operational instruments.

\section{Conclusions}

This research shows how the reuse of abandoned buildings and related open spaces constitutes a significant opportunity for achieving more liveable and healthier cities through the regeneration of inner city areas.

In a quite large majority of examined cases, design executes a strategy that combines the needs of reuse and preservation of a historic building of extraordinary value with the objectives of improving the health and quality of inner city life. The design solutions adopted, which have been tested in the case studies selected, tend to elicit the great potential of reuse, in terms of revitalization and improvement of living conditions. Finally, the research shows correlations between actions of adaptive reuse and the desired objectives of health and liveability of the city.

\section{References}

[1] Corkin, S. 2013. Permanent Present Tense. The Unforgettable Life of the Amnesic Patient H.M. New York: Basic Books.

[2] Coppola, A. 2012. Apocalypse Town. Bari: Laterza.

[3] Tweed, C., and Sutherland, M. 2007. "Built Cultural Heritage and Sustainable Urban Development." Landscape and Urban Planning 83: 62-9.

[4] Locatelli, V. 1990. "Sul Restauro (About Restoration)." Domus 715 (April): 21-8. (in Italian)

[5] Cramer, J., and Breitling, S. 2007. Architecture in Existing Fabric: Planning, Design, Building. Basel : De Gruyter.

[6] Lynch, K. 1968. The Image of the City. Cambridge : MIT (Massachusetts Institute of Technology).

[7] Rapoport, A. 1982. The Meaning of the Built Environment: A Non Verbal Communication Approach. New York: SAGE Publications.

[8] Dantzig, G. B., and Saaty, T. 1973. Compact City: A Plan for a Liveable Urban Environment. San Francisco, CA: W. $\mathrm{H}$. Freeman and Co.

[9] Wheeler, S., and Beatley, T. 2014. Sustainable Urban Development Reader. London and New York: Routledge, Taylor \& Francis Group.

[10] Moretti, E. 2012. The New Geography of Jobs. Boston: Houghton Mifflin Harcourt.

[11] Astorg, B. F. 2013. Old Buildings New Forms, New Directions in Architectural Transformations. New York: Monacelli Press.

[12] Plevoets, B., and Van Cleempoel, K. 2011. Adaptive Reuse As a Strategy towards Conservation of Cultural Heritage: A Literature Review. Vol. 118. Waterford: WIT (Waterford Institute of Technology).

[13] Powell, K. 2012. Architecture Reborn. Converting Old Buildings for New Uses. New York: Rizzoli International Publications, Inc.

[14] Reichlin, B., and Pedretti, B. 2011. Riuso del Patrimonio Architettonico (Reuse of the Architectural Heritage). Cinisello Balsamo: Mendrisio Academy Press. (in Italian) 